\title{
0 Traço Unário articulado ao recalque originário em Jacques Lacan
}

\author{
The Primal Trace linked to the primal repression in Jacques Lacan
}

\author{
Débora Maria Gomes Silveira
}

Psicóloga, Mestranda em Psicologia pela Universidade Federal de Minas Gerais (UFMG), Belo Horizonte, MG - Brasil, e-mail: deboramgs@yahoo.com.br

Recebido: $25 / 08 / 2010$ Received: 08/25/2010

Aprovado: 29/10/2010 Approved: 10/29/2010

\section{Resumo}

Considerando os seis gestos propostos por Jacques Lacan, no Seminário XXI (1974), como necessários ao enlaçamento do nó borromeano e tomando os seis movimentos de composição do nó como os tempos de estruturação do sujeito, o presente trabalho busca localizar, nos primórdios da constituição psíquica, a marca decisiva provocada pelo Traço Unário que lança o neonato irremediavelmente no campo simbólico. Neste sentido, o trabalho coteja a possibilidade de articulação entre as elaborações empreendidas por Lacan acerca do Traço Unário, a partir do Ein Einziger Zug de Freud, e o recalque originário, uma vez que o Traço, na medida em que atravessa o ser marcando-o com o simbólico, possibilita a fundação do inconsciente e a consequente divisão intrapsíquica recalcando decisivamente a condição de puro real do ser, possibilitando-o constituir-se como sujeito representado entre significantes. 0 Traço articulado ao recalque originário é tomado aqui, portanto, como marca presente no primeiro movimento de trançagem do qual o sujeito poderá emergir como um determinado particular.

Palavras-chave: Psicanálise. Traço Unário. Recalque originário. Constituição subjetiva.

\section{Abstract}

Taking into consideration the six gestures proposed by Jacques Lacan in Seminar XXI (1974) as necessary to the 'Borromean' knot and taking the six movements which compose the knot as the structuring phases of the subjectivity, the present work seeks to locate, by the inception of the psychic constitution, the conclusive mark entailed by the Primal Trace which launches the novice incurably into the symbolical field. In such sense, the work analyses the possibility of linkage between the elaborations conducted by Lacan about the 'Primal Trace', based on the 'Ein Einziger Zug' by Freud, and the originary repression, once the Trace, inasmuch as it goes through the being branding it with the symbolical, enables the foundation of the unconscious plus the resulting intra psychic division, decisively restraining the condition of pure real of the being, thus making it feasible to constitute himself as a subject represented among significants. The Trace linked to the originary repression is herein therefore taken as a present mark in the first movement of tracing, from which the subject might emerge as a determined particular.

Keywords: Psychoanalysis. Primal Trace. Originary repression. Subject constitution. 


\section{Introdução}

Em psicanálise, muitas são as possibilidades teóricas para considerar a fundação do inconsciente e a consequente constituição do psiquismo humano. E é somente a partir da perspectiva adotada que todo o raciocínio teórico e clínico que a psicanálise enseja pode se dar. Assim, destaca-se que a hipótese do inconsciente é condição para a psicanálise. Tudo de que trata a disciplina está fundado sobre os pilares da existência do sistema inconsciente. Nesse sentido, o presente trabalho propõe a discussão acerca da fundação do inconsciente a partir do conceito de Traço Unário retirado de Freud por Jacques Lacan. A questão aqui levantada se refere à possibilidade de articulação entre o recalque originário - instaurador da divisão consciente/ inconsciente - e a marca empreendida pelo Traço como localizadora desse atravessamento do ser promovido pelo recalque originário. Se este lança para o inconsciente algo do ser que jamais poderá ser alcançado ou apreendido pela consciência, mas que produz efeitos determinantes no sujeito que se constituirá, o que é recalcado e que consequências essa primeira operação apresenta?

Assim, o trabalho possibilita que algumas questões caras ao entendimento psicanalítico acerca da estruturação subjetiva sejam levantadas. Considerando que Lacan (1966 [1960]/1998) colocou o sujeito da psicanálise como o que é representado entre significantes, o que possibilita ao neonato sua primeira entrada no campo simbólico para que a cadeia significante se articule de modo a representá-lo? Percorrendo a linha de pensamento da qual se considera o recalque originário como primeira operação de fundação do psiquismo, é neste sentido que articulá-lo ao Traço Unário se faz possível, na medida em que este atravessa o ser puramente biológico marcando-o irremediavelmente pelo simbólico, recalcando sua condição de puro real para torná-lo ser de linguagem.

\section{0 recalque e 0 inconsciente: algumas consideraç̃oes}

Ainda que Freud tenha resistido à hipótese do inconsciente por um tempo de seus estudos psicopato- lógicos, o avanço de suas pesquisas o forçava, cada vez mais, a reconhecer que "restringir os fatos mentais aos que são conscientes e entremeá-los de fatos puramente físicos e neurais, 'rompe as continuidades psíquicas' e introduz lacunas ininteligíveis na cadeia de fenômenos observados" (Freud, 1915b/1996, p. 166). Supor a existência do inconsciente foi necessário à abertura de um campo imensamente fértil de novos conhecimentos (Freud, 1915b/1996) que viriam a ser conhecidos e nomeados por psicanálise. Nesta, "não temos outra opção senão afirmar que os processos mentais são inconscientes em si mesmos, e assemelhar a percepção deles por meio da consciência à percepção do mundo externo por meio dos órgãos sensoriais" (Freud, 1915b/1996, p. 176). Freud fundava um novo campo de estudo e, talvez, não pudesse abarcar a dimensão revolucionária de suas construções teóricas para o entendimento do psiquismo humano.

Considerar que existem processos mentais que são inconscientes estava diretamente ligado, já em Freud, aos seus estudos a respeito do recalque. Sem me deter nas infindáveis considerações freudianas e pós-freudianas que ensejam a construção teórica de ambas as noções - de inconsciente e de recalque -, cabe destacar que estas sempre estiveram ligadas em uma relação interdependente.

Aprendemos com a psicanálise que a essência do processo de recalque ${ }^{1}$ não está em pôr fim, em destruir a ideia que representa uma pulsão, mas em evitar que se torne consciente. Quando isso acontece, dizemos que a ideia se encontra em estado 'inconsciente', e podemos apresentar boas provas para mostrar que, inclusive quando inconsciente, ela pode produzir efeitos, incluindo até mesmo alguns que finalmente atingem a consciência (Freud, 1915b/1996, p. 171).

Assim, Freud considerava o recalque como o mecanismo psíquico responsável pela manutenção de uma ideia em estado inconsciente. Avançava no esforço de diferenciação dos conteúdos que, uma vez conscientes, poderiam ser recalcados ao inconsciente e aqueles que por força do recalque, nunca se tornariam conscientes, mas eram, constitucionalmente, parte do sistema inconsciente. Ao mesmo tempo em

1 Na edição utilizada, de 1996, a tradução dos termos die verdrändung e trieb é, respectivamente, repressão e instinto. Modifiquei os termos da edição para recalque e pulsão considerando as novas e mais precisas traduções existentes do vocabulário freudiano. 
que afirmava o recalque como mecanismo de defesa voltado, unicamente, a repelir algo da consciência e mantê-lo afastado desta, concluiu que tal mecanismo não poderia estar presente desde a origem, mas somente após a diferenciação estabelecida entre atividade psíquica consciente e inconsciente. Freud se viu impelido a estabelecer um recalque originário, "que consiste em interditar ao representante [...] psíquico da pulsão [...] a entrada e admissão consciente. Esse recalque estabelece então uma fixação, e a partir daí o representante em questão subsistirá inalterado e a pulsão permanecerá a ele enlaçada" (Freud, 1915/2004, p. 178-179). Tal afirmação surpreende por já conter a ideia de que algo das origens da constituição do psiquismo se dá a partir de uma fixação; algo que permanecerá, para sempre, inalterado e enlaçado à pulsão, de forma a determinar todo o funcionamento psíquico de um sujeito. Mesmo o que se dá no recalque propriamente dito - ou secundário - refere-se ao afastamento da consciência de representações derivadas do representante recalcado originariamente (Freud, 1915/2004). Ou seja, todo o trabalho de recalcamento secundário que se dá ao longo da vida de uma pessoa estará, sempre, em relação ao recalcado original, fixado no inconsciente, nunca passível de tornar-se consciente, mas extremamente provocador dos mais variados efeitos psíquicos na vida de um sujeito.

Nesse sentido, a propósito das formulações freudianas acerca da existência de um recalque diferenciado daquele a que chamou propriamente dito, o desenvolvimento da clínica e da teoria psicanalítica pôde considerar o recalque originário como fundador do inconsciente. Isto é, tal mecanismo se daria na própria contingência de isolamento de uma representação e da demarcação de algo que formaria o sistema inconsciente e, por consequência e diferenciação, o sistema consciente. Ainda que no artigo sobre O Recalque (1915), Freud o tenha considerado como mecanismo de defesa presente somente após efetuada a divisão intrapsíquica Cs / Inc, as reformulações da teoria psicanalítica puderam concluir que o recalque então definido como originário se dá em concomitância à constituição psíquica e, portanto, à separação entre as instâncias consciente e inconsciente. Mesmo que não o tenha dito desse modo, Freud já vislumbrava a relação de interdependência entre um e outro conceito: "Assim, parece-nos que o recalque e o inconsciente estão correlacionados de forma tão estreita que, enquanto não tivermos aprendido mais a respeito de como se estruturam as instâncias psíquicas e sobre a diferenciação entre inconsciente e consciente, não poderemos proceder a um exame aprofundado da natureza do recalque, teremos de postergá-lo" (Freud, 1915/2004, p. 178).

\section{0 inconsciente estruturado como linguagem}

Todo o trabalho de análise empreendido por Freud consistia, portanto, em articular os sintomas que seus pacientes lhe apresentavam às contingências recalcantes da vida do sujeito e aos sentidos ocultos de seu funcionamento inconsciente. Freud não perdia de vista, no entanto, a ideia de que algo de primordial e constitutivo estava presente em cada sujeito e o determinava a certas conformações e funcionamentos psíquicos. Embora a importância linguística esteja presente desde o princípio das elaborações psicanalíticas, a partir da formulação da possibilidade de "cura pela fala", fornecida a Freud pelo tratamento de Anna O. (1893), é com Lacan que a teorização do inconsciente estruturado como linguagem ganha força. Lacan colocou a descoberta freudiana do inconsciente em termos propriamente linguísticos, evocando os conceitos de significante e significado, metáfora e metonímia. Foi por meio da apresentação da noção de simbólico que a dimensão do sentido como inerente à própria possibilidade da psicanálise pôde ser destacada, o que permitiu a Lacan postular que a experiência freudiana está perfeitamente articulada com as leis pelas quais a linguagem se estrutura. "É justamente porque alguma coisa foi atada a alguma coisa semelhante à fala que o discurso pode desatá-la." (Lacan, 1998 [19571958]/1999, p. 13). Ao longo de toda sua produção, as noções de inconsciente estruturado como linguagem e de sujeito como o que se representa entre significantes são sempre mantidas, pois reiteram, para Lacan, o essencial da descoberta freudiana: a estruturação do psiquismo humano, em suas mais variadas formas de normalidade ou patologia, é puramente linguística, o que permite ao psicanalista intervir pela fala, na fala.

A estruturação linguística que Lacan confere ao inconsciente freudiano tem como elemento fundamental o significante e suas articulações ao significado. A ideia de Lacan está em estabelecer uma cadeia pela qual o significante transitaria, ligando-se aos mais variados significados e produzindo as significações manifestas pelas formações do inconsciente. É preciso considerar, 
no entanto, as funções do significante e do significado ligadas sob a dependência de um discurso, de uma história e de um código para se articularem em uma significação e produzirem algum sentido possível no registro simbólico (Lacan, 1998 [1957-1958]/1999). Neste sentido, Lacan confere à linguagem anterioridade em relação ao sujeito, ou seja, todo ser que chega ao mundo é, desde o início, imerso em um discurso que o antecede e determina, antes mesmo que o drama histórico e pessoal de cada um se inscreva. 0 sujeito, para Lacan, é o que se representa entre significantes (Lacan, 1966 [1960]/1998), e certas articulações entre significante e significado em uma cadeia são, desde o princípio, impostas ao ser recém lançado ao mundo simbolicamente organizado.

A questão está em saber o que permite ao sujeito se representar entre significantes, o que o insere nessa ordem simbólica que o antecede e, por conseguinte, funda seu psiquismo? Lacan empreende o esforço de fazer a distinção entre os registros simbólico, real e imaginário como essenciais ao entendimento do momento em que o ser se torna sujeito da e na linguagem: "A realidade é marcada de saída pela aniquilação simbólica" (Lacan, 1981 [19551956]/2002, p. 172). 0 que quer que se perceba, experiencie, tenha um primeiro acesso, já vem acompanhado de códigos significantes, o que implica não poder dizer que, para o homem, algo se apresente como pura e simples experiência. Não há realidade prévia ao simbólico para o homem e é em relação às origens da inserção do neonato no campo da linguagem, isto é, em relação a um primeiro momento, a uma primeira marca que faz do ser biológico sujeito, que a questão do Traço Unário se coloca. "Há necessidade estrutural de pôr uma etapa primitiva em que aparecem no mundo os significantes como tais" (Lacan, 1981 [1955-1956]/2002, p. 172).

\section{Traço Unário como recalque originário em Jacques Lacan}

O conceito de Traço Unário é retirado, por Lacan, do texto de Freud sobre a Psicologia de Grupo e a Análise do Ego (1921) em que o autor trata, no capítulo VII, da identificação "como a mais remota expressão de um laço emocional com outra pessoa" (Freud, 1921/1996, p. 115). É na definição de um modo de identificação, ao qual Freud chamou de regressiva, que se fala de uma assunção do ego das características do objeto ao qual se identifica e que, por sua vez, pode ser ou não uma pessoa amada. 0 que vale ressaltar aqui é que, em ambos os casos - de identificação com a pessoa amada ou com a não amada -, essa se dá de forma "parcial e extremamente limitada, tomando emprestado apenas um traço isolado da pessoa que é objeto dela" (Freud, 1921/1996, p. 117). É por esse traço único - Ein Einziger Zug - que Lacan retorna a Freud indicando a função de uma primeira identificação primitiva na possibilidade do neonato se inserir no campo da linguagem e se tornar sujeito representado entre dois significantes.

Considerando os seis gestos propostos por Lacan (1973-1974) como necessários ao enlaçamento do nó borromeano e tomando os seis movimentos como os tempos de estruturação do sujeito (Vorcaro, 1997), a incidência do traço deve ser compreendida como marca que insere o ser na linguagem e o torna sujeito desta irremediavelmente. Antes mesmo que um novo ser chegue ao mundo, o simbólico o precede. Todas as significações atribuídas ao primeiro momento em que uma mulher se sabe grávida - ou por aqueles que decidem por uma adoção - acompanharão a espera e a chegada do bebê. Sejam significações afetuosas ou hostis, estas carregam a história e as marcas da constituição subjetiva daquele que receberá o bebê no mundo.

Antes de qualquer experiência, antes de qualquer dedução individual, [...] algo organiza esse campo [simbólico], nele inscrevendo linhas de força iniciais. [...] Antes ainda que se estabeleçam relações que sejam propriamente humanas, certas relações já estão determinadas. Elas se prendem a tudo que a natureza possa oferecer como suporte, suportes que se dispõem em temas de oposição. A natureza fornece, para dizer o termo, significantes, e esses significantes organizam de modo inaugural as relações humanas, lhes dão as estruturas e as modelam [...] Antes de qualquer formação do sujeito, de um sujeito que pensa, que se situa aí - isso conta, é contado, e no contado já está o contador. [...] o jogo operatório operando em sua espontaneidade, sozinho, de maneira pré-subjetiva..." (Lacan, 1964, citado por Vorcaro, 1997, p. 71).

O bebê chega com percepções puramente sensoriais, que não contêm significação alguma a princípio. 0 que o bebê percebe são ritmos de presença/ ausência - presença/ ausência do alimento, presença/ ausência de luz ambiente. Suas reações são reflexas, ou seja, refletem um estado fisiológico qualquer 
(estímulos internos) ou estímulos externos como excesso de luz, ou de som. "Qualquer substituição desta condição é escolha feita por um outro agente, que tomará ou não a seus cuidados o organismo [...]" (Vorcaro, 1997, p. 71). A condição de nascimento do bebê humano exige, portanto, que ele seja, logo de saída, acolhido por um outro. Este outro, ao atuar como agente materno, é quem poderá sanar as necessidades do bebê que, neste momento, provêm da mera reação aos estímulos internos ou externos. É no ato de sanar as necessidades fisiológicas, interpretando-as e atribuindo-as o estatuto de apelo que o agente materno antecipa que há ali, naquele organismo, um sujeito que sente e deseja ser atendido. 0 lugar do desejo é, num primeiro momento, portanto, o lugar do agente materno que quer atender o desejo que ele supõe existir no bebê. Nesse momento, em que o desejo do ser está alienado ao desejo do outro, o sujeito só existe a partir da fala desse outro (submetido, ele mesmo, ao Outro da linguagem) e é na possibilidade de reconhecimento e diferenciação em relação ao Outro que sujeito se constituirá (Vorcaro, 1997).

O primeiro movimento de enlaçamento do nó que corresponde ao primeiro tempo de constituição subjetiva se refere à incidência da fissura Real no Simbólico (Vorcaro, 1997). É na impossibilidade de atendimento pleno do Outro materno às necessidades do bebê supostas como apelo, que o ritmo de tensão/ apaziguamento é falho.

Só a implicação do infans no apelo atestará sua imersão na linguagem. A articulação da criança no registro do apelo irá situá-la entre a noção de um agente que participa da ordem simbólica e o primeiro elemento de uma ordem simbólica - o par de termos opostos presença-ausência (mais-menos).Trata-se do tempo de atualização, na experiência, da estrutura mínima do significante, que agora incidirá no infans, como real, traçando o recalque originário (Vorcaro, 1997, p. 77).

0 encontro entre o agente materno e o suposto sujeito que o apela é marcado, desde o início, por um desencontro. Algo não comparece no lugar esperado de manutenção da situação alternante que tenciona e apazigua. $\mathrm{O}$ adiamento ou a precipitação do ritmo é marcado por uma lacuna fundamental que marca radicalmente o lugar de uma falta inominável. "A hiância acidental na sustentação da primeira estrutura simbólica, onde falta o que ainda não está representado, pontua o encontro faltoso
[...] fisgando o ser antes que ele possa figurar o que escapa à sua apreensão. [...] É a própria condição de falta que demarca o lugar, num traço que se introduz no real, perfurando-o" (Vorcaro, 1997, p. 78). Assim, o sujeito aparece no que lhe faz alteridade, no que incide como sentido no primeiro significante o grito da necessidade que se fez apelo - que, por apenas poder se prestar a intimar a recuperação da situação anterior de suposta plenitude, não poderá jamais se equivaler a essa recuperação, apenas traça a sua falta.

Algo do real, jamais apreensível, incide no ritmo simbólico que precedia o ser. Algo do real do Outro materno, que instaura a falta no sujeito que se constitui. Desta falta, marcada por esse Traço Unário, tem-se o primeiro tempo de constituição subjetiva que recalca, originariamente, toda e qualquer situação de alienação do ser ao desejo do Outro, bem como de alienação à organização simbólica humana. 0 ser, que se tornará sujeito, é marcado pelo simbólico que o atravessa e o insere na lógica significante. O significante unário, instaurador da falta é, no entanto, aquele que não se articula a um significado para produzir sentido, senão pela substituição significante que nunca poderá representar, em sua completude, aquilo que fez lacuna. 0 sujeito em constituição sai da situação de alienação pela privação que o traço instala. Da impossibilidade de atendimento pleno do apelo do sujeito suposto pelo agente materno, faz-se a hiância que possibilitará a busca do infans à alternância que lhe foi tirada e uma primeira assunção do desejo como próprio. Algo, portanto, resta dessa operação do traço que marca o caminho da alienação à privação. Resta um objeto perdido, jamais passível de ser reencontrado, fundador do inconsciente que interpela e impele o sujeito à repetição (Vorcaro, 1997).

O initium subjetivo se faz a partir da introdução primeira desse significante, Traço Unário que está antes do sujeito, esta mais simples singularidade de traço que entra no real. o Outro, que só pode oferecer significantes, não sabe responder-lhe, por faltar-lhe o que seria capaz de promover plenamente, só tem substitutos, mas é, ao mesmo tempo, o único desvio possível do infans para buscar encontrar aquilo de que se ressente. Disto, só resta a margem de um nada que marca o vestígio da perda, que só pode receber o nome de uma letra sem sentido: objeto $a$. Deste objeto que resiste à assimilação da função significante, mantendo-se vestígio de real no simbólico, perdido 
à significantização, depende o funcionamento significante e a repetição, que é errância em torno do vazio, que se depara com a inscrição incessante do que não se escreve, na procura do identicamente idêntico (Vorcaro, 1997, p. 80).

O objeto então perdido funda a pulsão na medida em que impele, portanto, ao retorno de um estado anterior. ${ }^{2} 0$ sujeito da psicanálise, para Lacan, é ser desejante por não poder, jamais, atingir aquilo que causa seu desejo. 0 objeto perdido, fonte de pulsão, instiga o sujeito à repetição ao empreender a busca perpétua por uma suposta plenitude inicial. A impossibilidade do reencontro se manifesta, no entanto, pela insuportabilidade do ser em tocar o real sem a imediação simbólica, bem como nos fenômenos desagregadores que a vivência corporal da completude enseja, tal como se observa, em seu extremo, na psicose. 0 que o Traço Unário recalca é o puro real do ser, a experiência não humanizada, inserindo-o, com uma primeira marca que instaura o inconsciente, na possibilidade de fazer articulação e substituição, em uma cadeia, do significante unário que o constitui como sujeito.

[...] nós nos encontramos em tudo aquilo que se pode chamar a bateria do significante, confrontada a esse traço único, a esse einziger Zug que já conhecemos, na medida em que, a rigor, ele poderia ser substituído por todos os elementos do que constitui a cadeia significante, suportá-la, essa cadeia por si só, simplesmente por ser sempre o mesmo. 0 que encontramos no limite da experiência cartesiana como tal do sujeito evanescente é a necessidade dessa garantia, do traço de estrutura o mais simples, do traço único, se ouso dizer, absolutamente despersonalizado, não somente de todo conteúdo subjetivo, mas também de toda a variação que ultrapasse esse único traço, desse traço que é um, por ser o traço único (Lacan, 1961-62, inédito - lição de 22/11/1961).

\section{Considerações finais}

Primeiramente, cabe destacar que o presente trabalho é fruto de estudos preliminares acerca da possibilidade de sistematização de uma teoria do recalque originário em Lacan a partir do conceito de Traço Unário. Neste sentido, considero que o texto permite o alcance de um primeiro objetivo: o de tentar localizar a elaboração lacaniana de Traço Unário como relativa aos momentos mais primordiais da constituição subjetiva. Assim, vê-se que por meio do raciocínio do traço como instaurador de uma marca que enseja toda a possibilidade de organização simbólica posterior do sujeito, bem como a partir da ideia do traço como o que racalca - e, portanto, funda - o objeto que, ao se perder, será o tempo todo visado e, ao mesmo tempo, contornado pela pulsão, pode-se pensar a formulação lacaniana do sujeito como aquele que se representa entre significantes. O significante unário, portanto, é aquele jamais representável ou articulável em cadeia, mas o que permite o deslizamento significante por representação, deslocamento e substituição de toda a cadeia que se constituirá para cada sujeito. É o significante que funda o inconsciente e a possibilidade deste produzir sentido, bem como aquele que instaura a falta jamais significantizada, jamais preenchida simbolicamente.

Desse modo, o Traço Unário é tomado como marca que lança o homem irremediavelmente no campo simbólico, retirando-o da condição de ser biológico para torná-lo ser de linguagem. É o primeiro registro de diferenciação e localização do ser como passível de constituir-se como sujeito e, portanto, primeira marca necessária à possibilidade de enlaçamento dos registros Real, Simbólico e Imaginário.

\section{Referências}

Freud, S. (1996). Estudos sobre a histeria. In S. Freud. Edição Standard Brasileira das Obras Psicológicas Completas de Sigmund Freud (C. M. Oiticica \& V. Ribeiro, trad., Vol. 2, pp. 13-350). Rio de Janeiro: Imago. (Originalmente publicado em 1983).

Freud, S. (1996). O inconsciente. In S. Freud. Edição Standard Brasileira das Obras Psicológicas Completas de Sigmund Freud (Vol. 14, pp. 163-222). Rio de Janeiro: Imago. (Originalmente publicado em 1915b).

2 Em consonância com o que Freud, em Além do Princípio do Prazer (1920), aborda sobre a compulsão à repetição instigada pela força pulsional cuja origem remonta à "necessidade de restaurar um estado anterior de coisas” (Freud, 1920/1996, p. 68). 
Freud, S. (1996). Além do princípio do prazer. In S. Freud. Edição Standard Brasileira das Obras Psicológicas Completas de Sigmund Freud (E. A. M. de Souza, trad., Vol. 18, pp. 11-75). Rio de Janeiro: Imago. (Originalmente publicado em 1920).

Freud, S. (1996). Psicologia de grupo e a análise do ego. In S. Freud. Edição standard brasileira das obras psicológicas completas de Sigmund Freud (E. A. M. de Souza, trad., Vol. 18, pp. 77-154). Rio de Janeiro: Imago. (Originalmente publicado em 1921).

Freud, S. (2004). 0 recalque. In S. Freud. Escritos sobre a psicologia do inconsciente (L. A. Hanns, H. Araújo, E. V. K. P. Susemihl \& M. R. Salzano, trad., Vol. 1, pp. 175193). Rio de Janeiro: Imago. (Originalmente publicado em 1915).

Lacan, J. (1961-1962). Le Seminaire: L'identification. Inédito.

Lacan, J. (1973-1974). Le Seminaire: Les nons dupes errent. Inédito.
Lacan, J. (1998). Subversão do sujeito e dialética do desejo no inconsciente freudiano. In J. Lacan. Escritos (V. Ribeiro, trad., pp. 807-842). Rio de Janeiro: J. Zahar. (Texto apresentado em 1960, nos Colóquios Filosóficos Internacionais de Royaumont: A dialética, e originalmente publicado em 1966).

Lacan, J. (1999). O Seminário, livro 5: As formações do inconsciente. (V. Ribeiro, trad.). Rio de Janeiro: J. Zahar. (Seminário ministrado nos anos de 1957 e 1958 e publicado originalmente em 1998).

Lacan, J. (2002). 0 Seminário, livro 3: As psicoses. (A. Menezes, trad.). Rio de Janeiro: J. Zahar. (Seminário ministrado nos anos de 1955 e 1956 e publicado originalmente em 1981).

Vorcaro, A. M. R. (1997). A criança na clínica psicanalítica. Rio de Janeiro: Cia de Freud. 
